\title{
CORRELATION AND PATH ANALYSIS IN MULBERRY SILKWORM, BOMBYX MORI L. ( LEPIDOPTERA: BOMBYCIDAE)
}

\author{
MD. ARIFUL HASAN, SAWDAGAR MAHFUZAR RAHMAN AND MD. KAMRUL AHSAN
}

Department of Zoology, Rajshahi University, Rajshahi-6205, Bangladesh

\begin{abstract}
The correlation and path analysis for nine quantitative characters in sixty five varieties of silkworm, Bombyx mori L. have been investigated. Out of all contributing characters studied expected cocoon yield $100 \mathrm{dfls}$ (ECY) showed significant positive associations with majority of the characters except filament size (FS) both at the phenotypic and genotypic levels. It suggested a strong association of these traits with yield. The direct and indirect effects of the component characters of ECY at phenotypic and genotypic levels were obtained separately. Here surviving percentage of larvae (SPL) and cocoon weight (CW) showed positive and high direct effect which indicated a true relationship as obtained from correlation values. Other characters showed positive correlations but the direct effects were either negative or negligible. In such a situation indirect causal factors are to be considered simultaneously.
\end{abstract}

Key words: Correlation, Path analysis, B. mori

\section{Introduction}

Silk yield is a complex entity and is not only polygenically controlled but also influenced by its component characters. In silkworm, Bombyx mori L. quantitative character, such as cocoon weight, shell weight, shell ratio, filament length etc. is jointly controlled by multiple genes and environmental factors (Reza and Rahman 2005, Zhao et al. 2007 and Ahsan and Rahman 2008). The selection of best genotypes depends on a number of characters and their interactions. Therefore, estimation of correlation in the genetic studies of quantitative characters is of special significance for selection of $B$. mori.

The problem of identifying the superior characters is usually aggravated by the confounding of environmental effects with genotypic effects. Therefore, direct selection is misleading and knowledge of these associated characters with yield at phenotypic and genotypic levels and screening of environmental effects will greatly help a breeder in his selection work. A careful assessment of the degree of variation and association and contribution of the component characters to yield must be analyzed to gain insight into the complexity of the mechanism. Experimental evidence is needed and the present investigation, therefore, is designed to find out correlations, direct and indirect path of yield contributing characters with yield for nine selected quantitative characters employing 65 varieties of $B$. mori. 


\section{Materials and Methods}

The material for the present investigation comprised of sixty five multivoltine (indigenous, developed and exotic) and bivoltine (developed and exotic) varieties of mulberry silkworm Bombyx mori L., collected from the Germplasm Bank of the Bangladesh Sericulture Research and Training Institute, Rajshahi. The names of the varieties are listed in Table1.

Table1.Varieties of Bombyx mori L. used in the experiment.

\begin{tabular}{|c|c|c|c|c|}
\hline 1. Nistari & 14. BSR-3 (p) & 27. BSR-95/10(P) & 40. Bipul & 53. Ziangsu $(\mathrm{P})$ \\
\hline 2. Nistari (P) & 15. BSR-3 (m) & 28. BSR-95/14(P) & 41. BSRI-83/1 & 54. Dong $34(\mathrm{M})$ \\
\hline 3. Nistari (M) & 16. BSR-10 (m) & 29. BSR-95/22(P) & 42. BSRI-83/2 & 55. Dong $34(\mathrm{P})$ \\
\hline 4. Nistari L & $\begin{array}{l}\text { 17. Nistid white } \\
\text { (P) }\end{array}$ & 30. BSR-98/1(P) & 43. BSRI-83/3 & 56. BV (M) \\
\hline 5. Nistari G & 18. BSR-JB & 31. BSR-98/2(P) & 44. BSRI-85/1 & 57. BV (P) \\
\hline 6. ISK & 19. BSR-IM(P) & $\begin{array}{l}32 . \\
\text { BSR2000/1 (GM) }\end{array}$ & 45. BSRI-85/2 & 58. RB (M) \\
\hline $\begin{array}{l}\text { 7. MBY- } \\
011 \mathrm{~S}(\mathrm{P})\end{array}$ & 20. BSR-(GL) & 33. BSR-02/1(M) & 46. BSRI-85/3 & 59. RB (P) \\
\hline 8. BN P & 21. BSR-92/2(P) & 34. BSR-02/2(P) & 47. BSRI-J & 60. RB-001 (M) \\
\hline 9. BN (M) & 22. BSR-92/5(P) & 35. BSR-02/3 & 48. Urboshi-1 & 61. RB-001 (P) \\
\hline 10. NN-7B (P) & 23. BSR-92/7(P) & 36. BSR-03/1 & 49. Urboshi-4 & 62. RB-111 \\
\hline 11. NM-7B (M) & 24. BSR-92/8(P) & 37.BSR-03/2 & 50. BSRI-801 & 63. RB-112 \\
\hline $\begin{array}{l}\text { 12. BSR- } \\
1 \text { white (p) }\end{array}$ & 25. BSR-92/14(P) & 38. $\mathrm{O}_{5}$ & 51. BSRI-802 & 64. RB-SB (M) \\
\hline $\begin{array}{l}\text { 13. BSR- } \\
1 \text { white }(\mathrm{m})\end{array}$ & 26. BSR-92/16(P) & 39. $\mathrm{R}_{1} \mathrm{~S}_{1}$ & 52. Ziangsu 12-J & 65. RB-SP (P) \\
\hline
\end{tabular}

The eggs of these varieties were brushed ( $3 \mathrm{dfls}$ for each genotype) in a randomized design each with three replications. The rearing was conducted in the rearing house No. 2 of the the Bangladesh Sericulture Research and Training Institute, Rajshahi. Scientific technology of silkworm rearing was followed according to Krishnaswami (1978) and Rahman (1983). Data recorded for this study were: total number of eggs laid per female (TEL), egg hatching percentage (EHP), mature larval weight (MLW), surviving percentage of larvae (SPL), cocoon weight (CW), shell weight (SW), filament length (FL), filament size (FS) and estimated cocoon yield out of $100 \mathrm{dfls}$ (ECY). The phenotypic and genotypic correlations were calculated by the following formula:

$$
r\left(x_{1} x_{2}\right)=\frac{\operatorname{COV}\left(x_{1} x_{2}\right)}{\sqrt{V\left(x_{1}\right) V\left(x_{2}\right)}}
$$


The path-coefficient analysis was carried out as described by Deway and Lu (1959) at phenotypic and genotypic levels. The residual effect is a composite variable that includes all other unaccounted factors affecting yield in this study and is assumed to be independent to the remaining variables. It was calculated from the formula as proposed by Wright (1921).

$$
\text { Residual effect }(\chi)=1-R^{2}
$$

Where,

$$
R^{2}=P_{1 y}+P_{2 y} r_{2 y}+\ldots \ldots \ldots \ldots \ldots . . .+P_{n y} r_{n y}
$$

$\mathrm{R}^{2}$ is the required multiple correlation coefficient and is the amount of variation in yield that can be accounted for by the component characters.

\section{Results and Discussion}

The phenotypic and genotypic correlations between all pairs of characters analysed have been shown in Table 2 . In the present study the component characters which showed positive correlations with ECY were TEL, EHP, MLW, SPL, CW, SW, FL and FS. These were also significant except association of FS with ECY both at phenotypic and genotypic levels. It suggested a strong association of these traits with yield. Samson and Krishnaswami (1980) found significant positive correlations of mature larval weight with cocoon weight and shell weight in $B$. mori which agree with the present result. Petkov (1981a) found a negative phenotypic correlation between cocoon weight and silk richness

Table 2. Phenotypic $\left(r_{p}\right)$ and genotypic $\left(r_{g}\right)$ correlation coefficients between all pairs of characters in silkworm, $B$. mori.

\begin{tabular}{llllllllll}
\hline Variables & & TEL & EHP & MLW & SPL & CW & SW & FL & FS \\
\hline EHP & $\mathrm{r}_{\mathrm{p}}$ & $0.62^{* *}$ & & & & & & & \\
& $\mathrm{r}_{\mathrm{g}}$ & $0.66^{* *}$ & & & & & & & \\
MLW & $\mathrm{r}_{\mathrm{p}}$ & $0.77^{* *}$ & $0.44^{* *}$ & & & & & & \\
& $\mathrm{r}_{\mathrm{g}}$ & $0.85^{* *}$ & $0.50^{* *}$ & & & & & & \\
SPL & $\mathrm{r}_{\mathrm{p}}$ & $0.36^{* *}$ & 0.17 & $0.36^{* *}$ & & & & & \\
& $\mathrm{r}_{\mathrm{g}}$ & $0.37^{* *}$ & 0.18 & $0.41^{* *}$ & & & & & \\
CW & $\mathrm{r}_{\mathrm{p}}$ & $0.74^{* *}$ & $0.43^{* *}$ & $0.87^{* *}$ & $0.35^{* *}$ & & & & \\
& $\mathrm{r}_{\mathrm{g}}$ & $0.76^{* *}$ & $0.45^{* *}$ & $0.97^{* *}$ & $0.36^{* *}$ & & & & \\
SW & $\mathrm{r}_{\mathrm{p}}$ & $0.43^{* *}$ & 0.13 & $0.55^{* *}$ & -0.04 & $0.65^{* *}$ & & & \\
& $\mathrm{r}_{\mathrm{g}}$ & $0.44^{* *}$ & 0.13 & $0.61^{* *}$ & -0.04 & $0.66^{* *}$ & & & \\
FL & $\mathrm{r}_{\mathrm{p}}$ & $0.54^{* *}$ & 0.17 & $0.61^{* *}$ & -0.13 & $0.71^{* *}$ & $0.89^{* *}$ & & \\
& $\mathrm{r}_{\mathrm{g}}$ & $0.55^{* *}$ & 0.18 & $0.68^{* *}$ & -0.13 & $0.73^{* *}$ & $0.91 * *$ & & \\
FS & $\mathrm{r}_{\mathrm{p}}$ & 0.07 & 0.07 & 0.20 & 0.11 & $0.25^{*}$ & $0.56^{* *}$ & 0.20 & \\
& $\mathrm{r}_{\mathrm{g}}$ & 0.07 & 0.08 & 0.22 & 0.12 & $0.26^{*}$ & $0.57^{* *}$ & 0.21 & \\
ECY & $\mathrm{r}_{\mathrm{p}}$ & $0.71^{* *}$ & $0.39^{* *}$ & $0.79^{* *}$ & $0.77^{* *}$ & $0.87^{* *}$ & $0.42^{* *}$ & $0.42^{* *}$ & 0.23 \\
& $\mathrm{r}_{\mathrm{g}}$ & $0.72^{* *}$ & $0.41^{* *}$ & $0.88^{* *}$ & $0.77^{* *}$ & $0.87^{* *}$ & $0.43^{* *}$ & $0.42^{* *}$ & 0.24 \\
\hline
\end{tabular}

\footnotetext{
* Significant at $5 \%$ level, $* *$ Significant at $1 \%$ level
} 
and in another study Petkov (1981b) reported high positive correlations between these traits. High phenotypic and genotypic correlations between cocoon weight and shell weight have been observed by Ozdzenska and Kremky (1987) which is in good agreement with the present finding. They also reported high positive correlations between survival rate and cocoon yield, and a negative correlation between hatchability and number of eggs per gram in B. mori. Similar results were also reported by Mistri and Jayaswal (1992) and Singh et al. (1994), Ahsan and Rahman (2008) and Ahsan and Rahman (2010). The present result on correlation studies showed that genotypic correlations were always higher than the corresponding phenotypic correlations. These low phenotypic correlations could be due to a modifying effect of environment on the association of characters at the genetic level (Rahman 1984). Similar findings were also reported by Sen et al. (1976) in Antheraea mylitta and by Ozdzenska and Kremky (1987), and Ahsan and Rahman $(1997,2008)$ in B. mori.

The direct and indirect effects of the component characters on expected cocoon yield out of $100 \mathrm{dfls}$ were obtained separately and are presented in Table 3 . The residual effects were

Table 3. Path-coefficient analysis showing direct and indirect effect of eight quantitative characters at phenotypic $(\mathrm{P})$ and genotypic $(\mathrm{G})$ levels upon estimated cocoon yield per 100 dfls.

\begin{tabular}{|c|c|c|c|c|c|c|c|c|c|c|}
\hline \multirow{2}{*}{$\begin{array}{l}\text { Variabl } \\
\text { es }\end{array}$} & & \multicolumn{8}{|c|}{ Indirect effect via } & \multirow{2}{*}{$\begin{array}{l}\text { Total } \\
\text { correlatio } \\
\text { n with } \\
\text { ECY }\end{array}$} \\
\hline & & TEL & EHP & MLW & SPL & $\mathrm{CW}$ & SW & $\mathrm{FL}$ & FS & \\
\hline \multirow[t]{2}{*}{ TEL } & $P$ & $\underline{0.0145}$ & 0.0090 & 0.0112 & $\underline{0.0052}$ & 0.0108 & 0.0062 & 0.0078 & 0.0010 & \multirow{2}{*}{$\begin{array}{l}0.71 * * \\
0.72 * *\end{array}$} \\
\hline & G & $\underline{0.0191}$ & -0.0125 & 0.0162 & -0.0070 & 0.0146 & 0.0083 & -0.0105 & -0.0013 & \\
\hline \multirow[t]{2}{*}{ EHP } & $P$ & 0.0041 & $\underline{0.0066}$ & 0.0029 & 0.0011 & 0.0028 & 0.0008 & 0.0011 & 0.0005 & $0.39^{* *}$ \\
\hline & G & 0.0080 & $\underline{0.0123}$ & 0.0061 & 0.0022 & 0.0055 & 0.0016 & 0.0022 & 0.0010 & $0.41 * *$ \\
\hline \multirow[t]{2}{*}{ MLW } & $\mathrm{P}$ & 0.0105 & 0.0059 & $\underline{0.0136}$ & 0.0049 & 0.0119 & 0.0075 & 0.0083 & 0.0027 & $0.79 * *$ \\
\hline & G & & 0.0697 & $\underline{0.1407}$ & 0.0574 & 0.1371 & 0.0853 & 0.0954 & 0.0313 & $0.88 * *$ \\
\hline \multirow[t]{2}{*}{ SPL } & $\mathrm{P}$ & $0.1861-$ & 0.0896 & 0.1893 & $\underline{0.5204}$ & 0.1833 & -0.0191 & -0.0663 & 0.0595 & $0.77 * *$ \\
\hline & G & 0.1894 & 0.0918 & 0.2113 & $\underline{0.5182}$ & 0.1865 & -0.0198 & -0.0662 & 0.0607 & $0.77 * *$ \\
\hline \multirow[t]{2}{*}{$\mathrm{CW}$} & $\mathrm{P}$ & & 0.2834 & 0.5814 & 0.2341 & $\underline{0.6646}$ & 0.4347 & 0.4726 & 0.1655 & $0.87 * *$ \\
\hline & $\mathrm{G}$ & & 0.2472 & 0.5405 & 0.1998 & $\underline{0.5550}$ & 0.3682 & 0.4033 & 0.1420 & $0.87 * *$ \\
\hline \multirow[t]{2}{*}{ SW } & $\mathrm{P}$ & & 0.0000 & -0.0001 & 0.0000 & $-\overline{0.0001}$ & -0.0001 & -0.0001 & -0.0001 & $0.42 * *$ \\
\hline & G & 0.0024 & 0.0007 & 0.0034 & -0.0002 & 0.0032 & $\underline{0.0056}$ & 0.0050 & 0.0032 & $0.43^{* *}$ \\
\hline \multirow[t]{2}{*}{ FL } & $P$ & 0.0046 & -0.0014 & -0.0052 & 0.0011 & $0.0060^{-}$ & 0.0076 & -0.0085 & -0.0017 & $0.42 * *$ \\
\hline & G & 0.0029 & -0.0010 & 0.0036 & 0.0007 & 0.0039 & $0.0048^{-}$ & -0.0054 & -0.0011 & $0.42 * *$ \\
\hline \multirow[t]{2}{*}{ FS } & $\mathrm{P}$ & 0.0003 & 0.0003 & 0.0008 & 0.0005 & 0.0010 & 0.0024 & 0.0009 & $\underline{0.0042}$ & 0.23 \\
\hline & $\mathrm{G}$ & 0.0001 & 0.0001 & 0.0003 & 0.0001 & 0.0003 & 0.0007 & 0.0003 & $\underline{0.0013}$ & 0.24 \\
\hline
\end{tabular}

Residual effect $0.05163,0.04477$ at phenotypic level and genotypic level respectively. Underlined figures denote direct effect. * Significant at $5 \%$ level, ${ }^{* *}$ Significant at $1 \%$ level 
also calculated at phenotypic and genotypic level and these were 0.05163 and 0.04477 respectively. Results obtained from path analysis revealed that direct and indirect effects on yield of different characters were inconsistent in the majority of the cases which recall the significant role of the environment. In a correlation and path coefficient study if the value of the correlation coefficient and the direct effect are almost equal then it explains a true relationship and a direct selection will be effective. In the present investigation the direct effect of SPL and CW on ECY was positive and high, which indicated a true relationship as obtained from correlation values. Ahsan et al. (1999) reported a true relationship between effective rate of rearing by weight and estimated cocoon yield out of 100 dfls. Rahman and Rahman (1992) noted that fifth instar larvae and larvae at spinning exhibited a relationship with respect to both length and volume in Philosamia ricini. Siddiqui et al. (1992) noted direct positive effect of CW, SCR, ERR and larval period on silk yield and positive significant correlation at both the phenotypic and genotypic levels except larval period. Similar results were also reported for total number of eggs laid per female, egg hatching percentage, mature larval weight, cocoon weight, shell weight and filament length by Ahsan et al. $(1999,2000)$. Other characters showed positive correlations but the direct effects were either negative or negligible. In such a situation indirect causal factors are to be considered simultaneously (Singh and Chaudhary 1979).

\section{References}

Ahsan, M. K. and S. M. Rahman. 1997. Correlation and path coefficient analysis in indigenous varieties of silkworm, Bombyx mori L. Univ. j. zool. Rajshahi Uni. 16: 35-38.

Ahsan, M. K. and S. M. Rahman. 2008. Genetic variability and correlation analysis in hybrids of silkworm, Bombyx mori L. for egg characters. Univ. j. zool. Rajshahi Univ. 27: 13-16.

Ahsan, M. K. and S. M. Rahman. 2010. Genetic variation of some quantitative traits in ten exotic varieties of silkworm, Bombyx mori L. Univ. j. zool. RajshahiUniv. 29: 69-71.

Ahsan, M. K., S. M. Rahman and I. A. Ali. 1999. Inheritance of some quantitative traits in fifteen indigenous varieties of silkworm. Bombyx mori L. Univ. j. zool. Rajshahi Univ. 18: 7983.

Ahsan, M. K., S. M. Rahman and I. A. Ali. 2000. Variability of some quantitative traits in the hybrids of silkworm, Bombyx mori L. Univ. j. zool. Rajshahi Univ. 19: 20-24.

Deway, D. R. and K. H. Lu. 1959. A correlation and path-coefficient analysis of components of crested wheat seed production. Agron. J. 51: 511-518.

Krishnaswami, S. 1978. New technology of silkworm rearing. Central Silk Board, India. 23pp.

Mistri, P. K. and K. P. Jayaswal. 1992. Studies on phenotypic correlations between some economic traits of silkworm, Bombyx mori L. Bull. Seric. Res. 3: 26-29.

Ozdzenska, B. and J. Kremky. 1987. Estimation of heritability and genetic, phenotypic and environmental correlations in outbreed population of mulberry silkworm, Bombyx mori L. Sericologia 27: 633-638.

Petkov, N. 1981a. Variability and correlations between some characteristic features of silkworm, Bombyx mori L. Thivotnov Dnauki. 18(3): 83-86.

Petkov, N. 1981b. Variability and correlations between some characteristic features of silkworm, Bombyx mori L. Genet. Sel. 12(4): 286-291. 
Rahman, M. S. and S. M. Rahman. 1992. Correlations, path-coefficients and the application of discriminant function selection in Eri silkworm, Philosamia ricini Boisd. I. correlation studies in P. ricini. Bull. Seric. Res. 3: 33-39.

Rahman, S. M. 1983. Technology of mulberry silkworm rearing suitable for the climatic condition in Bangladesh. Reshom 1: 71-79.

Rahman, M. S. 1984. Studies on the genetic improvement of eri silkworm, Philosamia ricini Boisd. of Bangladesh, Ph.D. thesis Department of Zoology, Rajshahi University.

Reza, A. M. S. and S. M. Rahman. 2005. Genetic parameters of some yield and yield contributing traits in silkworm, Bombyx mori L. Univ. j. zool Rajshahi Univ. 24: 55-58.

Samson M. V. S. and S. Krishnaswami. 1980. Some useful correlation studies of silkworm and its products such as cocoon, pupa, shell and egg wt. Indian J. Seric. 19: 4-8.

Sen, S. K., A. K. Sengupta, M. G. Das and M. S. Jolly. 1976. Studies on the genetic variability correlations, path co-efficient analysis and discriminant functions in Antheraea mylitta D. Indian J. Seric. 15: 9-14.

Siddiqui, A. A.; M..Sinha, A. Kumar, C. M. Bajpayi and S. S. Sinha. 1992. Selection of better ganotypes through path-coefficient analysis in segnegating generation of Autheraea mylitt D. Serieologia. 32(2): 239-245.

Singh, R., Chandrashekharaiah and M. V. Samson. 1994. Selection stratigies in relation to correlation and heritability in silkworm, B. mori L. Bull. Sericul. Res. 5: 37-41.

Singh, R.K. and B. D. Chaudhury. 1979. Biometrical Method in Guantitative Genetic analysis. Kalyani Publishers, New Delhi. India. 304pp.

Wright, S. 1921. Correlation and causation. J. Agric. Res. 20: 557-585.

Zhao, Y., K. Chen and S. He. 2007. Key principles for breeding spring-and-autumn using silkworm varieties: from our experience of breeding $873 \times 874$. Caspian J. Environ. Sci. 5: 57-61. 